\title{
Investigation of the contact performance of machined surface morphology
}

\author{
Pengyang $\mathrm{Li}^{\mathrm{a}}{ }^{\mathrm{b}}$, Yanfei Zhai ${ }^{\mathrm{a}}$, Shikun Huang ${ }^{\mathrm{a}}$, QuandaiWang ${ }^{\mathrm{a},{ }^{*}, \text { Weiping Fu }{ }^{\mathrm{a}} \text {, Hongping Wang }}{ }^{\mathrm{c}}$ \\ a. Department of Mechanical Engineering and Automation, Xi'an University of Technology, Xi'an, \\ 710048, PR China \\ b. State Key Laboratory of Mechanical Transmission, Chongqing University, Chongqing, 400044, \\ PR China \\ c. Department of Mechanical and Electrical Engineering, Tianshui Normal University, Tianshui \\ 741001, PR China
}

E-mail addresses:151812915@QQ.com (Q.Wang).

\begin{abstract}
Engineering practices have indicated that surface textures and topography greatly affect the mechanical performance of contact interfaces. The effect of machined surface morphologies on the contact performance results, including average surface gap, contact area ratio, and the volume of plastically deformed material, is investigated. Depending on the machined parameters, the studied surfaces are generated using computer simulation. The elasto-plastic contact of rough surfaces is analyzed by means of semi-analytical method (SAM) and minimization of complementary energy. Results indicate that with increasing the interval of texture, average surface gap remains invariant while contact area ratio and the volume of plastically deformed material decreases.
\end{abstract}

Keywords: Surfaces morphology; Elasto-plastic contact; Contact performance 


\section{Introduction}

Machining processes produce surface topography with different characteristics, which may influence the contact performance of rough surfaces [1]. Wang et al [2] developed a numerical simulation method for generating rough surfaces with desired autocorrelation function (ACF) and statistical parameters, Gaussian, non-Gaussian, isotropic, and nonisotropic rough surfaces can be generated by this method. However, the parameters are not from real machined surface. There are various machining parameters such as, cutting speed, feed rate and tool nose radius that are known to have a large impact on surface quality $[3,4]$. Under the same roughness, different cutting processes could yield the surfaces with different mechanical performance of contact interfaces. Therefore, it is required to investigate the influence of cutting parameters on the contact performance of surface morphology. As the relationship between contact performance and the machining parameters is studied, the surface with better contact performance could be processed through optimizing the cutting parameters [5-7].

During past decades, the simulation of machined surface has been developed, where the turned and milled surfaces were generated using simulation. In the early study of turning simulation, scientists primarily focused on contour simulation, most of which emulated the surface topography of orthogonal cutting process along feed direction. Lin and Chang [8] employed a simulation model where the effects of the relative motion between the cutting tool and the workpiece and the effects of tool geometry were used to simulate the surface geometry. Based on the 3-dimensional dynamic analysis, Kelly et al [9] established a cutting model to simulate the turning surface morphology considering the influences of cutting and regenerative vibrations. By considering the effects of errors occurred in machining process, Yao et al [10] presented a method considering the surface forming process and the machining error to model the orthogonal cutting process using the virtual manufacturing technology. With the development of high-precision technology, numerous studies have been performed on surface simulation in high-precision turning area. Cheung and Lee [11] predicted the turning surface by studying the kinematics of ultra-precision diamond turning process. Clocke et al [12] put forwarded a method to simulate the surface morphology in high speed orthogonal turning using finite element software DEFORM 2D. During the cutting process, many dynamic factors influence the surface finish. Zhou and Cheng [13] proposed a dynamic cutting model to simulate the nano- and micro turning surface considering external and internal disturbances of dynamic cutting. Therefore, it is established that turning surface can be generated as the cutting model.

On the other hand, many simulation techniques have been proposed on milled surface. For instance, Kim and Chu [14] presented a texture superposition method to evaluate the surface asperity of milled surfaces and to find three-dimensional surface topography. Compomanes and Altintas [15] came up with a milling model to predict the 3-dimensional surface finish topography, where the cutting vibration of mill cutter in feed direction was considered. In 
order to simulate the surface topography of end milling, a new type of cutting model had been used in reference [16]. The milling model incorporated the static and dynamic deflection of milling cutter to make the simulation profile closer to the experimental one. Imani and Layegh [17] proposed a computational algorithms by considering cutting conditions to simulate milled surface; an end-milling surface could be generated through a realistic surface texture model. Lavernhe et al [18] used a numerical simulation for the prediction of surface finish in 5-axis high-speed machining which could also be used to generate milled surface. The simulated models of milled surface were used to study the end milling process, such as to discuss the surface roughness parameter [19]. Recently, a geometrical model was proposed to predict the surface roughness of milled surface [20]. Considering the geometrical deviation of the milling cutter, it can be concluded that the generated topography was closed to the experimentally obtained results. Based on the morphology of machined surface in high-speed milling, the aforementioned models were good enough to generate milled surface. Based on the aforementioned simulation methods used for milled surface, the simulation of face milled surface can be generated to investigate the contact interfaces.

Numerous studies on surface texture have been undertaken due to their significance on mechanical performances $[21,22]$. In these studies, the surface contact properties were investigated through the contact mechanics, such as stress, strain, contact fatigue, stiffness and damping ability. It has been reported that hard turning produces compressive residual stresses in a deep subsurface which contribute to a long fatigue life [5]. The cutting parameters greatly affects the surface integrity aspects of the hard turned parts and consequently, the fatigue life [6]. It is reported that the effect of residual stress on fatigue life is more pronounced than the effect of surface roughness [7]. Ren et al [23] concluded that different machined surfaces evidently affected the lubrication contact performance by introducing line-contact mixed-elasto hydrodynamic lubrication problems occurred in rough surfaces. From these studies, it is evident that a relationship exists among surface quality, turning process parameters and fatigue behavior. Therefore, it is vital to understand the effects of machined surface morphology on the mechanical performance of contact interfaces.

Although many studies have shown interesting results on the relationship between machining parameters and contact performance, a very few have investigated the elasto-plastic contact problem of the machined surface while the contact occurs in a static contact stage. Thus, this work aims at studying elasto-plastic contact problem of two engineered surfaces, such as turned and milled surfaces which are simulated under different operating conditions.

\section{Simulation model of turned and milled surfaces}

Based on the results of literature, simulation models of turning and milling surfaces are presented in this paper. Depending on the trajectory of the cutter relative to the workpiece, the machined surfaces are generated herein. In 
order to achieve a comprehensive outcome, factors in the cutting process, such as spindle runout, cutting vibrations in both radial and feed direction are considered in the simulation model. The process of the simulation is shown in Fig. 1.

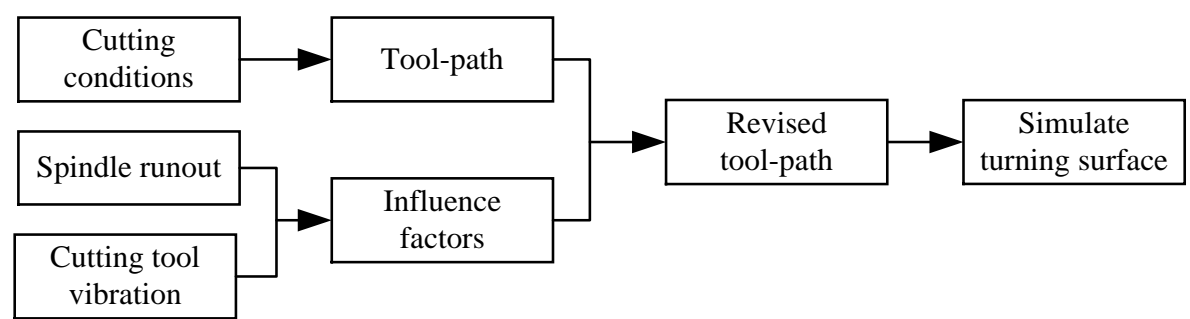

Fig. 1. The flow chart of the simulation used in the present study.

\subsection{Simulation model of turned surface}

\subsubsection{Model establishment}

In this paper, the turning model is based on the orthogonal cutting process as the cutting edge orthogonal to cutting speed. As shown in Fig. 2, the workpiece is cut under spindle speed, $\mathrm{n}$; $\mathrm{w}$ is the chip thickness; $x(t)$ and $y(t)$ are the relative position between tool and workpiece in radial and feed direction, which resulted from the effects of spindle runout and cutting vibration. Based on the outcome of $x(t)$ and $y(t)$, the tool-path can be obtained. Thus, the kinetic model of tool is established in two directions during the turning process, as shown in Fig. 3 and Fig. 4.

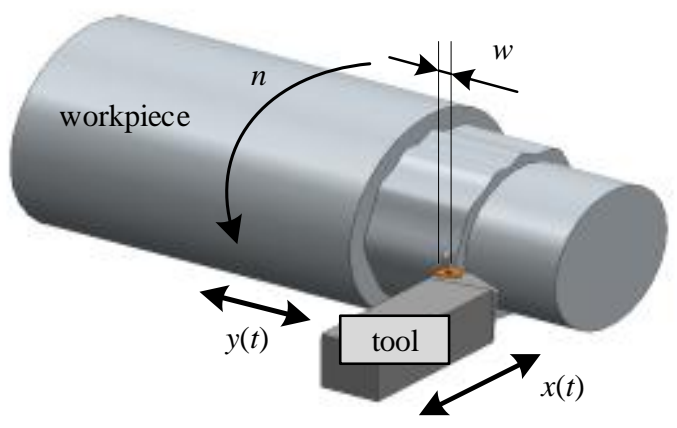

Fig. 2. Schematic of orthogonal cutting process.

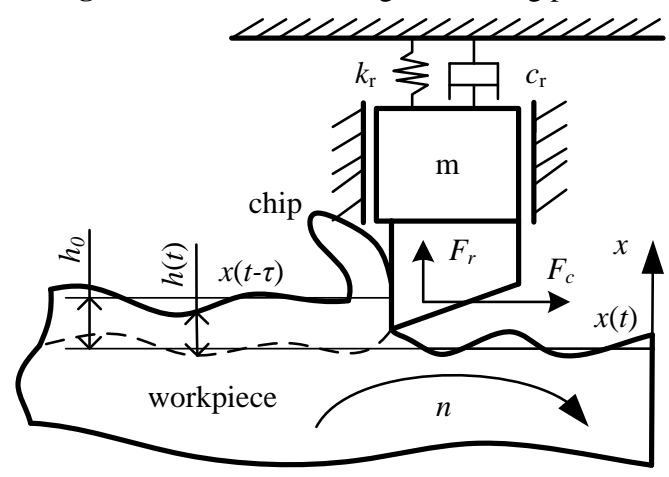

Fig. 3. Kinetic model of tool in radial direction 


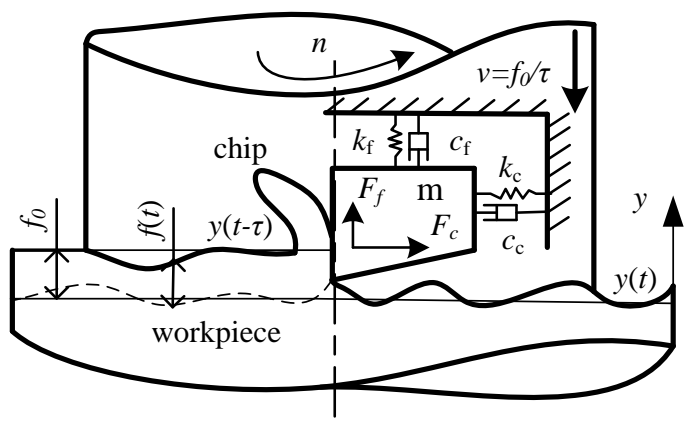

Fig. 4. Kinetic model of tool in feed direction

The tool holder is assumed to be a compliant structure and suffers from cutting vibration in radial and feed directions. Therefore, the cutting parameters e.g., the chip thickness denoted by $h(t)$ and the depth of cut denoted by $f(t)$ are changed over time during the cutting process. As shown in Fig. 3 and Fig. 4, the instantaneous chip thickness and depth of cut are given by

$$
\begin{aligned}
& h(t)=x(t-\tau)-x(t)=\Delta h(t)+h_{0} \\
& f(t)=y(t-\tau)-y(t)=\Delta f(t)+f_{0}
\end{aligned}
$$

where $h_{0}$ is the constant chip thickness, $f_{0}$ is the constant depth of cut, and $\tau=2 \pi / n$ is the rotation period of the workpiece.

According to the kinetic model of tool illustrated in Fig. 3 and Fig. 4, the motion of the cutting tool in radial and feed directions can be written as follows

$$
\begin{aligned}
& \ddot{m}(t)+c_{r} \dot{x}(t)+k_{r} x(t)=F_{r} \\
& \ddot{m}(t)+c_{f} \dot{y}(t)+k_{f} y(t)=F_{f}
\end{aligned}
$$

where $m, c_{r}, c_{f}, k_{r}$ and $k_{f}$ are the modal mass, the damping and the stiffness parameters in radial and feed directions respectively. Then the cutting force can be measured using the following Eqs.[24]

$$
\begin{gathered}
F_{r}=K_{r} f(t)(h(t))^{q} \\
F_{f}=K_{f} f(t)(h(t))^{q}
\end{gathered}
$$

where $K_{x}$ and $K_{y}$ are the cutting coefficients, $q$ is an exponent.

In this study, the spindle runout is supposed to affect the value of chip thickness only. Thus, as the cutting conditions (such as chip thickness, depth of cut, spindle rotation speed and the geometry of insert nose radius) are given and the influences factors of turning process are considered, the tool-path during the turning process can be found out, and the simulated surface can finally be generated.

\subsubsection{Model validation}

In order to verify the validity of the present model, an experiment of orthogonal cutting process is conducted to 
compare with the simulation result. The cutting conditions and the cutting tool parameters are displayed in Table 1 and Table 2 respectively. The stiffness and damping ratio of tool holder can be obtained by testing the modal of tool holder in radial and feed directions. In this study, m, damping ratio, $k_{r}$ and $k_{f}$ are found to be $0.261 \mathrm{~kg}, 0.04,11.4286 \mathrm{~N} / \mu \mathrm{m}$ and $16 \mathrm{~N} / \mu \mathrm{m}$, respectively.

Table 1 Cutting conditions of turning experiment

\begin{tabular}{ccccccc}
\hline \hline $\begin{array}{c}\text { Machine } \\
\text { tool }\end{array}$ & $\begin{array}{c}\text { Chip } \\
\text { thickness }(\mathrm{mm})\end{array}$ & $\begin{array}{c}\text { Depth of } \\
\text { cut }(\mathrm{mm})\end{array}$ & $\begin{array}{c}\text { Spindle } \\
\text { speed(r/min) }\end{array}$ & $\begin{array}{c}\text { Radius of workpiece } \\
(\mathrm{mm})\end{array}$ & $\begin{array}{c}\text { Workpiece } \\
\text { material }\end{array}$ & $\begin{array}{c}\text { None cutting } \\
\text { fluid }\end{array}$ \\
\hline C6140A & 0.5 & 0.2 & 800 & 20 & 1045 steel & \\
\hline \hline
\end{tabular}

Table 2 Cutting tool parameters

\begin{tabular}{ccccccc}
\hline \hline Tool & Material & $\begin{array}{c}\text { Corner } \\
\text { radius }(\mathrm{mm})\end{array}$ & $\begin{array}{c}\text { Spindle } \\
\text { speed }(\mathrm{r} / \mathrm{min})\end{array}$ & $\begin{array}{c}\text { Main } \\
\text { angle }\left({ }^{\circ}\right)\end{array}$ & $\begin{array}{c}\text { Rake } \\
\text { angle }\left({ }^{\circ}\right)\end{array}$ & $\begin{array}{c}\text { Inclination } \\
\text { angle }\left({ }^{\circ}\right)\end{array}$ \\
\hline $90^{\circ}$ migraine tools & YT15 & 0.52 & 800 & 90 & 10 & 0 \\
\hline \hline
\end{tabular}

As the spindle runout is associated with the spindle speed, the kinetic equation of spindle runout can be defined as follows [25]

$$
\ddot{s}(t)+2 \xi \omega_{n i} \dot{s}(t)+\omega_{n i}^{2} s(t)=A_{i} \omega_{n i}^{2} \cos (\omega t)
$$

where $s$ is the displacement of spindle, $A_{i}$ is the vibration amplitude of the $i$-th order natural frequency, $\omega_{n i}$ is i-th order natural frequency of spindle and $\xi$ is the damping ratio, $\omega$ is the excitation frequency which can be determined using the natural frequency and spindle speed. As the spindle angular frequency does not exceed the first order natural frequency, the first order modal equation is capable to represent the motion equation of spindle.

Fig. 5 shows the surface obtained from turning experiment and simulation. In order to compare the results, contours of two profiles are superimposed in the feed direction (Fig. 6). It is clear that the simulated surface is closed to the experimental surface. Therefore, it can be said that the presented simulation model of turning process is proved to be valid for the applied conditions.

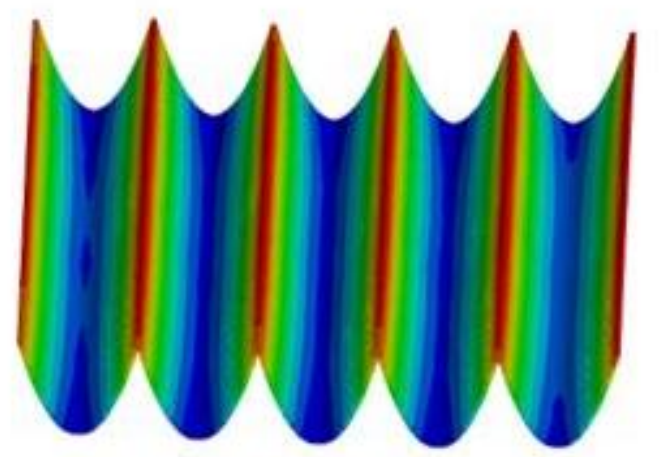

(a)

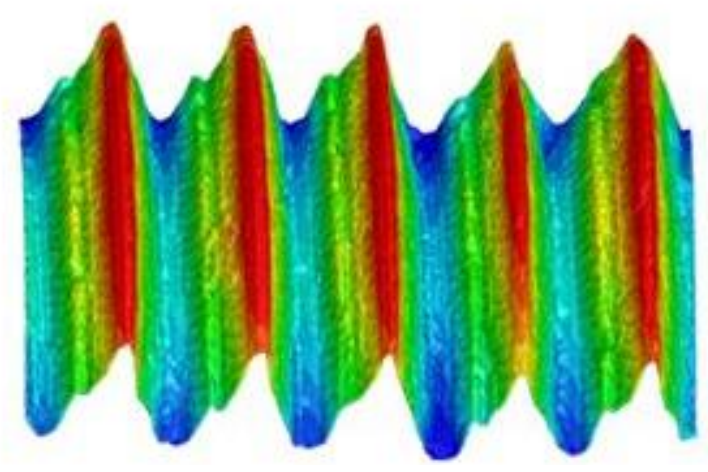

(b)

Fig. 5. (a) Simulated surface and (b) experimental surface 


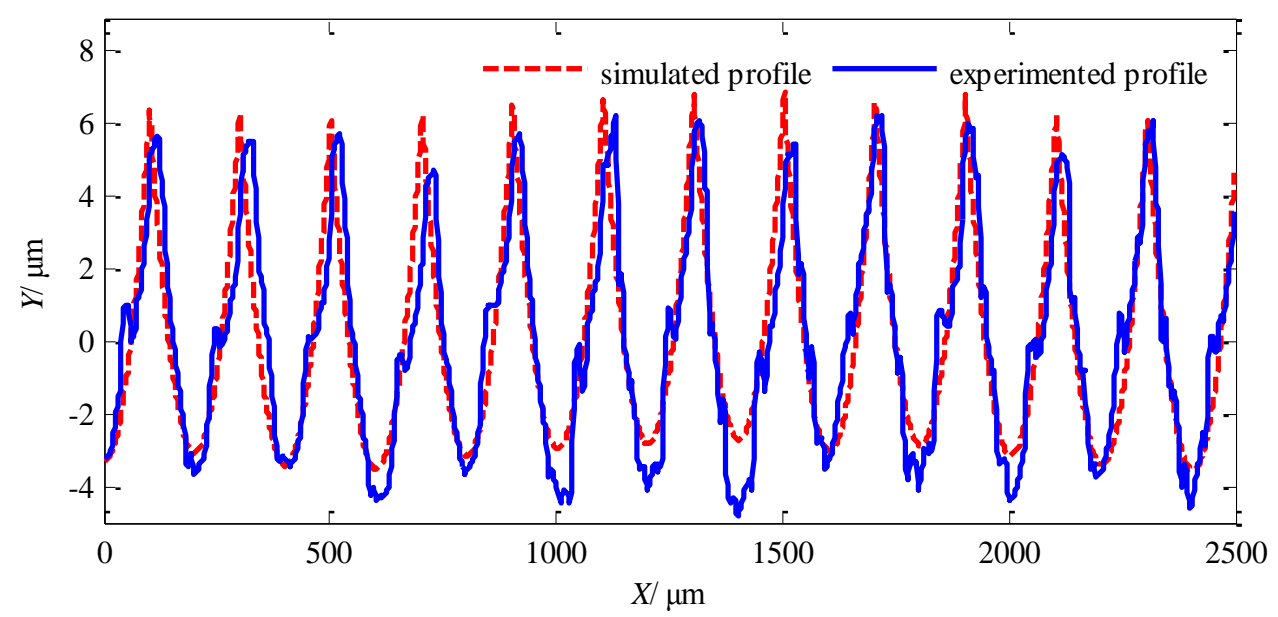

Fig. 6. A comparison between simulated contour and experimental contour in feed direction

\subsection{Simulation model of milled surface}

\subsubsection{Model establishment}

In this section, the simulation model of end milling process is established and the milling state is analyzed. The milling cutter used in the simulation model is shown in Fig. 7. In the Fig. 7, $\varepsilon_{\mathrm{a}}$ and $\varepsilon_{\mathrm{r}}$ are the deviation of the tooth caused by the installation error in axial and radial directions, respectively; $\Phi$ is the tilt angle of the tooth; $i$ denotes the number of the tooth. In fact, as the geometry and the installation location of every tooth are not equal to each other, the relative position errors, such as $\varepsilon_{\mathrm{a}}, \varepsilon_{\mathrm{r}}$ and $\Phi$ have an evident influence on milling surface morphology. Thus, these factors are considered during simulation model.

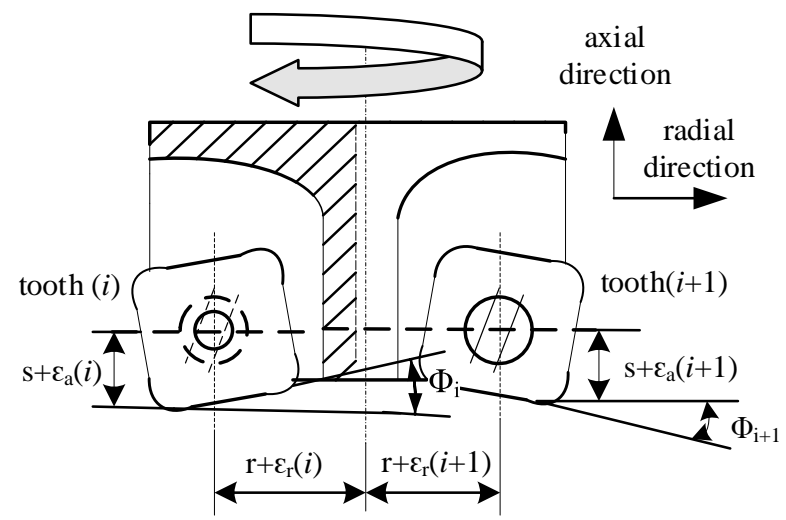

Fig. 7. Schematic of face milling cutter
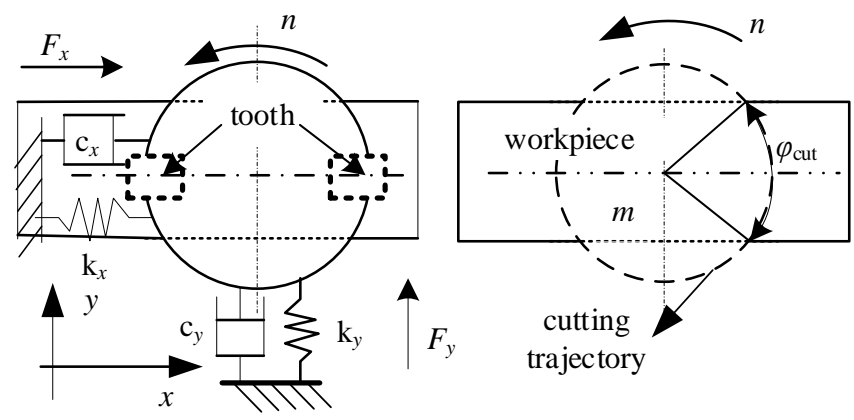

Fig. 8. Kinetic model of face milling cutter 
As the face milling cutter is supposed to be a compliant structure during the milling process, the cutter is assumed to experience bending motion in $x$ and $y$ directions. Thus, the milling system can be modeled as a 2 degree of freedom oscillator excited by cutting force as shown in Fig. 8. Then the governing equations of cutter are given in the following form.

$$
\begin{aligned}
& \ddot{m} \dot{x}(t)+c_{x} \dot{x}(t)+k_{x} x(t)=F_{x} \\
& \ddot{m} \dot{y}(t)+c_{y} \dot{y}(t)+k_{y} y(t)=F_{y}
\end{aligned}
$$

where $m, c_{x}, c_{y}, k_{x}$ and $k_{y}$ are the modal mass, the damping and the stiffness parameters in $x$ and $y$ directions, respectively. And the cutting force can be calculated by using following Eqs [26]

$$
\begin{gathered}
F_{x}=h f K_{x}(t) \\
F_{y}=h f K_{y}(t) \\
K_{x}(t)=\sum_{i=1}^{N}\left\{g_{i}(t) \times\left(K_{t} \times A+K_{n} \times B\right) \times B\right\} \\
K_{y}(t)=\sum_{i=1}^{N}\left\{g_{i}(t) \times\left(-K_{t} \times B+K_{n} \times A\right) \times B\right\} \\
g_{i}(t)=\left\{\begin{array}{l}
1, \varphi \in \varphi_{\text {cut }} \\
0, \varphi \notin \varphi_{\text {cut }}
\end{array}\right. \\
A=\cos \left(\frac{2 \pi n}{60} t+(i-1) \frac{2 \pi}{N}\right) \\
B=\sin \left(\frac{2 \pi n}{60} t+(i-1) \frac{2 \pi}{N}\right)
\end{gathered}
$$

where $h$ is the chip thickness, $f$ represents the depth of cut, $K_{t}$ and $K_{n}$ are the cutting coefficients in tangential and normal directions of cutting force, $N$ denotes the total number of teeth, $n$ is the spindle rotation speed.

In the simulation model, the spindle runout is assumed to affect depth of cut but does not have any impact upon the chip thickness. Therefore, the trajectory of the tooth during milling process can be worked out as the milling conditions (such as chip thickness, depth of cut, spindle rotation speed and the geometry of the tooth) are given and the influence factors of end milling process are took into consideration. Finally the simulation of end milling face can be implemented.

\subsubsection{Model validation}

In order to valid the presented model, the end milling cutting is performed using face milling cutter. The end milling experiment is conducted on the CNC; the cutting tool is the face milling cutter with two teeth, as shown in Fig. 7. The geometry of face milling cutter is displayed in Table 3 . As the spindle runout of CNC is similar to the spindle runout of lathe, the kinetic equation of spindle runout in milling process can be written as Eq. (7).The cutting 
parameters and the modal parameters used in the end milling experiment are shown in Table 4.

Table 3 Geometry of face milling cutter

\begin{tabular}{ccccccc}
\hline \hline $\mathrm{r}(\mathrm{mm})$ & $\Phi\left(^{\circ}\right)$ & $\begin{array}{c}\text { insert tool } \\
\operatorname{radius}(\mathrm{mm})\end{array}$ & $\varepsilon_{r}(1) /(\mu \mathrm{m})$ & $\varepsilon_{r}(2) /(\mu \mathrm{m})$ & $\varepsilon_{a}(1)-\varepsilon_{a}(2) /(\mu \mathrm{m})$ & $\begin{array}{c}\text { number } \\
\text { of teeth }\end{array}$ \\
\hline 25 & 1.5 & 0.8 & 40 & 70 & 2 & 2 \\
\hline \hline
\end{tabular}

Table 4 Parameters for milling process

\begin{tabular}{cc}
\hline \hline Spindle natural angular frequency $\omega_{n} /(\mathrm{rad} / \mathrm{s})$ & 920 \\
damping ratio $\xi$ & 0.004 \\
modal mass of milling cutter $m /(\mathrm{kg})$ & 2.5 \\
$K_{t} /\left(\mathrm{N} / \mathrm{m}^{2}\right)$ & $5.36 \times 10^{8}$ \\
$K_{n} /\left(\mathrm{N} / \mathrm{m}^{2}\right)$ & $1.87 \times 10^{8}$ \\
$\Phi_{\text {cut }} /(\mathrm{rad})$ & 0.823 \\
chip thickness $h /(\mathrm{mm})$ & 0.5 \\
spindle rotation speed $n /(\mathrm{r} / \mathrm{min})$ & 2000 \\
depth of cut $f /(\mathrm{mm} / \mathrm{r})$ & 0.2 \\
workpiece material & duralumin \\
\hline \hline
\end{tabular}

Fig. 9 shows the surface obtained from end milling experiment and simulation model. In order to compare the results, contours of two profiles in the feed direction are superimposed (Fig. 10). By comparing the simulated and experimental result, it is evident that the simulated surface is closed to the experimental surface. Therefore, it can be concluded that the presented simulation model of end milling process valid for certain condition.

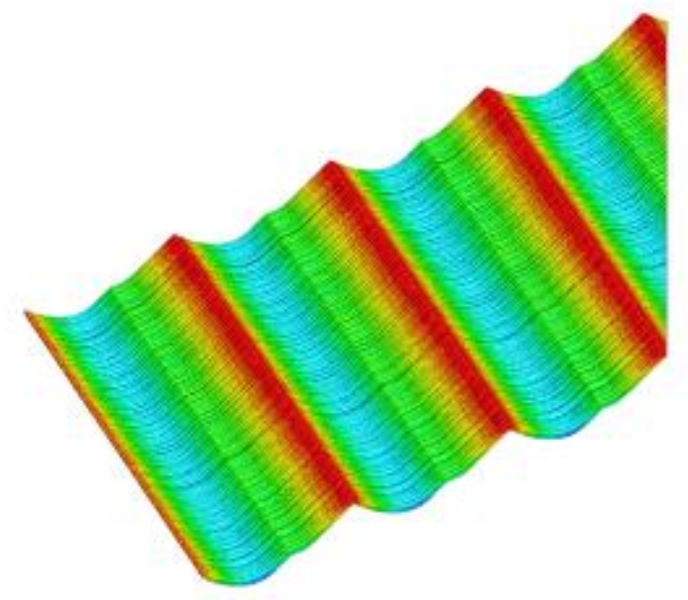

(a)

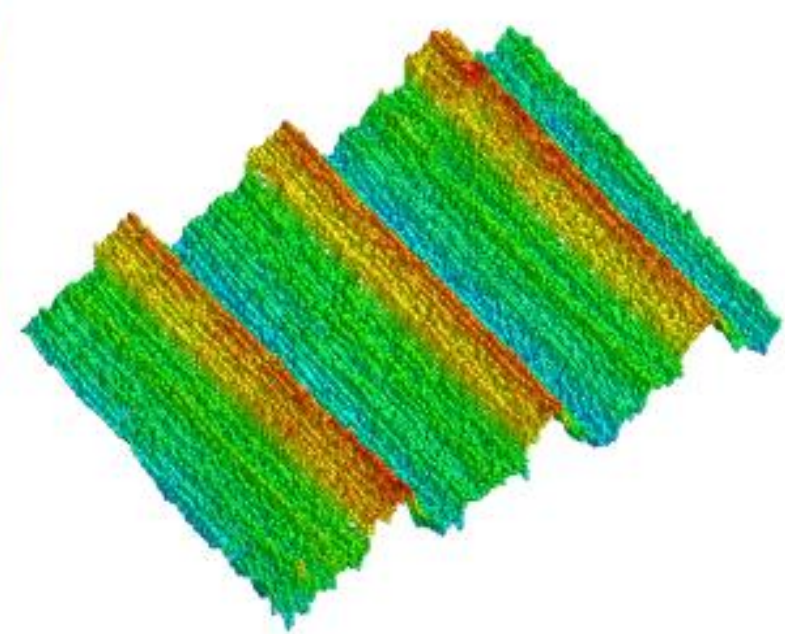

(b)

Fig. 9. (a) Simulated surface and (b) experimental surface 


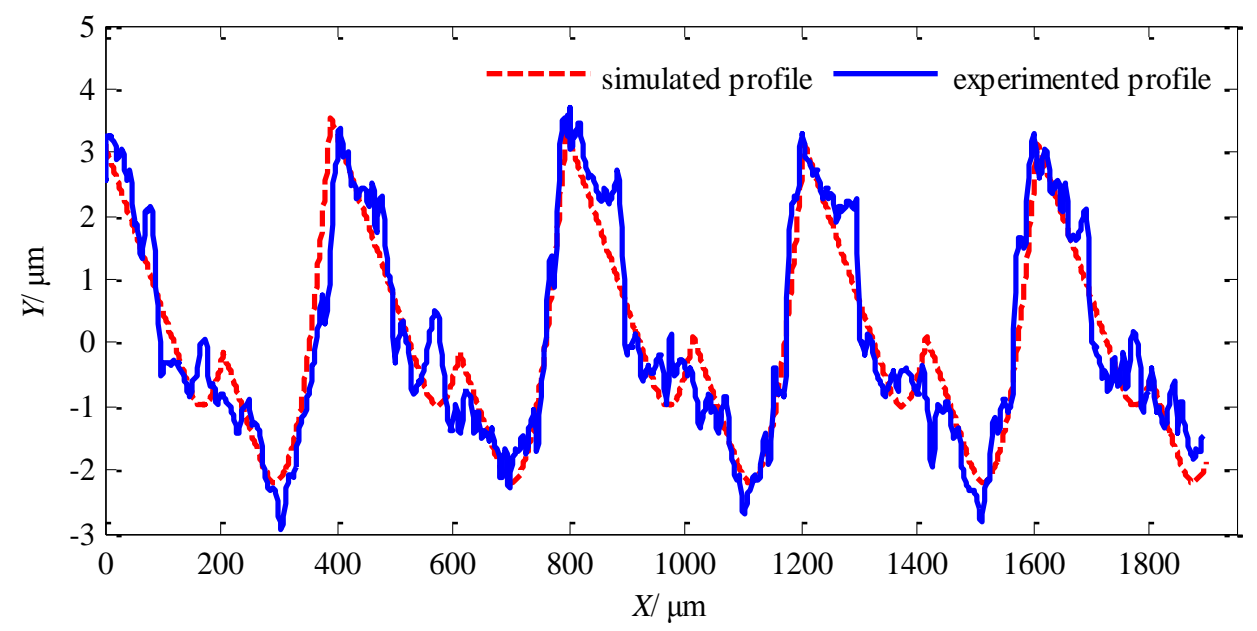

Fig. 10. A comparison between simulated contour and experimental contour in feed direction

\section{Elasto-plastic contact model}

In this work, the elasto-plastic contact model is based on the half-space theory which consists of a rigid smooth flat surface against a rough elasto-plastic flat surface, as shown in Fig. 11.

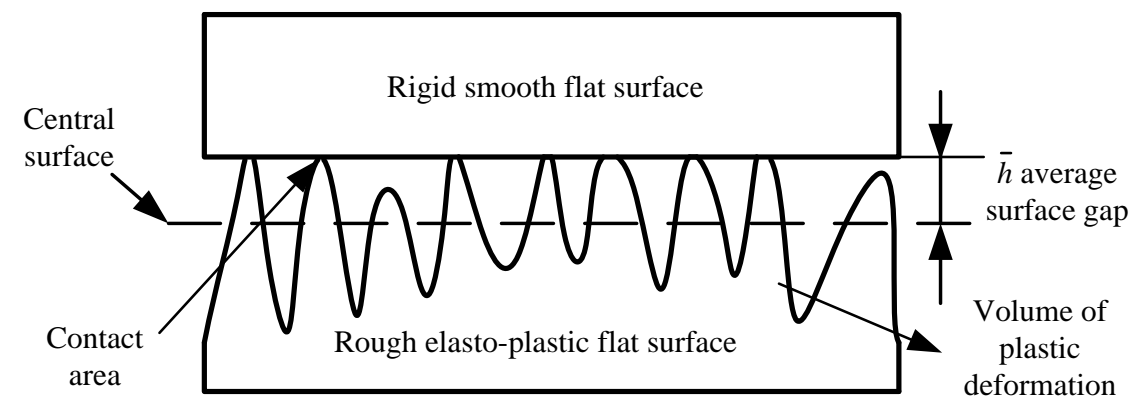

Fig. 11. The elasto-plastic contact model

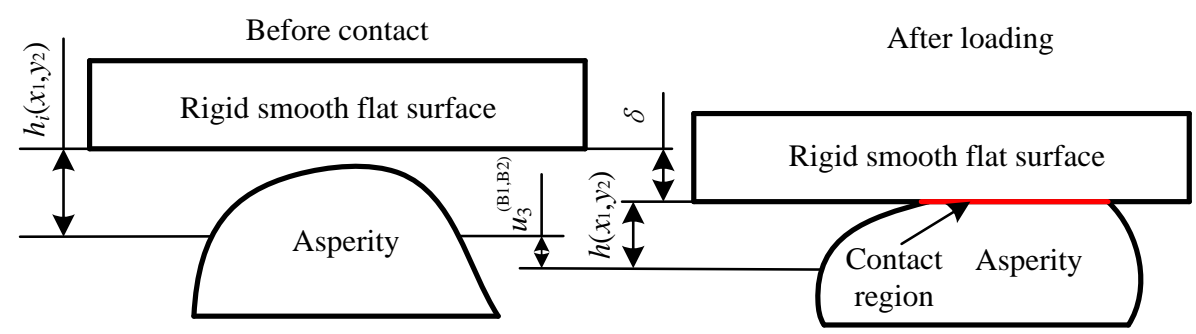

Fig. 12. Schematic of surface gap variation

Since the contact model has been selected, a tool that can simulate three dimensional elastic-plastic contacts is needed. The tool must consider the evolution of contact pressure and stress field with plastic flow. Therefore, a resolution of the elastic-plastic contact using the finite element (FE) method is considered, and the SAM is conducted to solve the contact equations. The contact behaviors can be formulated in terms of the surface gap $(h)$, the vertical displacement of two bodies $\left(u_{3}^{B 1+B 2}\right)$ and the rigid-body approach $(\delta)$, as shown in Fig. 12. As the two bodies are contacted each other, the surface gap $(\mathrm{h}(\mathrm{x}, \mathrm{y}))$, can be written as follow:

$$
h(x, y)=h_{i}(x, y)+u_{3}^{B 1+B 2}(x, y)+\delta
$$


where, $h_{i}(x, y)$ is the initial interfacial gap that can be obtained from original surface topographies of contact bodies. The contact conditions are maintained such that the bodies cannot interpenetrate each other. Thus, $h(x, y)$ must be positive or nil. If $h(x, y)$ is not nil, no contact occurs and no pressure is transmitted. Therefore, the condition can be expressed as following equations.

$$
\left\{\begin{array}{l}
h(x, y)=0 \Rightarrow p(x, y) \geq 0 \quad(x, y) \in \Gamma_{C} \\
h(x, y)>0 \Rightarrow p(x, y)=0 \quad(x, y) \notin \Gamma_{C}
\end{array}\right.
$$

where $\Gamma_{\mathrm{c}}$ is real contact area.

Based on the Boussinesq integral equation [27], the deformation due to contact pressure can be calculated using following equation (19),

$$
u_{3}^{p}(x, y)=\int_{-\infty}^{\infty} \int_{-\infty}^{\infty} G^{p}\left(x x^{\prime}, y y^{\prime}\right) \times p\left(x^{\prime}, y^{\prime}\right) d x^{\prime} d y^{\prime}=G^{p} \times p
$$

where, $G^{p}(x, y)=1 / \pi \times E^{*} \times \sqrt{x^{2}+y^{2}}$ is the Green function, and $E^{*}=E / 1-v^{2}$, is the Young's modulus. Thereafter, the contact problem was modeled using an equation subjected to boundary constrains. The discrete convolution and fast Fourier transform algorithm [28] is applied to solve the rough surface contact problems iteratively. If the surface residual deformation becomes zero, the model will be simple and purely elastic contact model.

In order to determine the plastic zone, the information of the subsurface stress field is required. The total stress is decomposed into two parts, an elastic part and a residual part.

$$
\sigma_{i j}=\sigma_{i j}^{e}+\sigma_{i j}^{p}
$$

where, $\sigma_{i j}^{e}$ is the stress due to contact pressure which can be obtained by the product of pressure and its influence coefficient, according to Zhang et al. [29]. However, the residual stress, $\sigma_{i j}^{p}$ was calculated using the method proposed by Liu et al. [30]. Frequency response functions (FRF) of the elastic stress in a half-space and a transform procedure to obtain the FRF of the residual stress are numerically discussed in detail in [27].

The von-Mises criterion indicated in Eq. (21) was chosen to identify the onset of plastic deformation.

$$
f=\sigma_{V M}-g(\lambda)=\sqrt{\frac{3}{2} S_{i j}: S_{i j}-g(\lambda)}
$$

where, $\sigma_{V M}$ is the von-Mises equivalent stress, $\lambda=\sum d \lambda=\sum\left(\sqrt{2 d \varepsilon_{i j}^{p} d \varepsilon_{i j}^{p} / 3}\right)$ is the effective accumulative plastic strain, $g(\lambda)$ is the yield strength function. Therefore, the term, $g(0)$ equals to the initial yield strength $\sigma_{Y}$, and $S_{i j}=\sigma_{i j}-\sigma_{k k} \delta_{i j} / 3$ is the deviatoric stress. In the present study, the linear hardening law is used to express the yield strength function, as shown in Eq. (22).

$$
g(\lambda)=Y+\frac{E_{t}}{1-E_{t} / E} \times \lambda
$$

where, $E_{t}$ is the elasto-plastic tangential modulus. Based on the subsurface stress values and the plasticity model, plastic deformation can be determined using an increment-based approach [31, 32]. Above all, it can be concluded that the proposed contact model can calculate contact variants. 


\section{Results and discussions}

The presented model is used to investigate the effect of machined surface morphologies on the contact performance results, such as the average surface gap, the contact area ratio, and the volume of plastically deformed material. Different types of machined surfaces are generated based on the simulated program. Thereafter, three-dimensional simulations were conducted for a frictionless contact having a rigid half-space and an elasto-plastic body. The nominally flat surface was contacted with the rigid body under a mean pressure, $\bar{p}$.

Dimensionless average pressure was considered as input factor in this analysis where following relation was also considered:

$L=\bar{p} / Y$,

where, $\mathrm{Y}$ is the initial yield strength before strain hardening.

Following (three dimensionless) performance variables were the outcomes of the simulation:

(1) Dimensionless average surface gap, $\Gamma=\bar{h} / R_{q}$,

(2) Contact area ratio $\Lambda=A_{c} / A_{n}$, and

(3) Dimensionless volume of plastically deformed zone $\Omega=V_{p} / A_{n} R_{q}$.

where, $\bar{h}$ is the average surface gap; $A_{n}$ is the nominal contact area; and $V_{p}$ is the total volume in the body where plastic strains occurred. It is necessary to calculate the maximum value of von-Mises stress, $\sigma_{-}$max to analyze the concentrated stress.

In order to investigate the effects of machining parameters on rough-surface contacts, the aforementioned performance variables were compared to the dimensionless average pressure $(L)$. Here dimensionless average pressure $(L)$ was varied from lower to higher level while others remain constant. Therefore, 9 simulated turned surfaces and 9 simulated milled surfaces were generated. In addition, different surface roughness, $R_{\mathrm{q}}$ values of rough surfaces are considered. The detailed simulation parameters of machined surfaces are shown in Table 5 and Table 6 . In this study, the area size of joint surface used in the joint contact analysis is set to be $216 \times 216 \mu \mathrm{m}^{2}$. Thus, the surface roughness of corresponding simulated surfaces is listed in Table 7. The material of elasto-plastic surfaces is used to be structural steel with Young's modulus, $E=210 \mathrm{GPa}$, Poisson's ratio, $\nu=0.3$ and yield stress, $\sigma_{s}=461.5 \mathrm{MPa}$.

Table 5 Cutting conditions of turning simulation

\begin{tabular}{cccccc}
\hline \hline $\begin{array}{c}\text { Turning } \\
\text { surfaces }\end{array}$ & $R(\mathrm{~mm})$ & $f(\mathrm{~mm} / \mathrm{r})$ & $h(\mathrm{~mm})$ & $n(\mathrm{r} / \mathrm{min})$ & $\begin{array}{c}\text { diameter of the } \\
\text { workpiece }(\mathrm{mm})\end{array}$ \\
\hline T 1-1 & 0.8 & 0.080 & 0.3 & 800 & 40 \\
T 1-2 & 1.2 & 0.098 & 0.3 & 800 & 40 \\
T 1-3 & 1.5 & 0.109 & 0.3 & 800 & 40 \\
T 2-1 & 0.8 & 0.131 & 0.3 & 800 & 40 \\
T 2-2 & 1.2 & 0.160 & 0.3 & 800 & 40 \\
T 2-3 & 1.5 & 0.178 & 0.3 & 800 & 40 \\
T 3-1 & 0.8 & 0.173 & 0.3 & 800 & 40 \\
T 3-2 & 1.2 & 0.212 & 0.3 & 800 & 40 \\
T 3-3 & 1.5 & 0.237 & 0.3 & 800 & 40 \\
\hline \hline
\end{tabular}


Table 6 Cutting conditions of milling simulation

\begin{tabular}{ccccccc}
\hline \hline $\begin{array}{c}\text { Milling } \\
\text { surfaces }\end{array}$ & $R(\mathrm{~mm})$ & $f(\mathrm{~mm} / \mathrm{r})$ & $h(\mathrm{~mm})$ & $n(\mathrm{r} / \mathrm{min})$ & $\Phi\left({ }^{\circ}\right)$ & $\begin{array}{c}\text { cutting radius of face } \\
\text { milling cutter(mm) }\end{array}$ \\
\hline M 1-1 & 0.8 & 0.084 & 0.5 & 2000 & 1.5 & 25 \\
M 1-2 & 1.2 & 0.100 & 0.5 & 2000 & 1.5 & 25 \\
M 1-3 & 1.5 & 0.110 & 0.5 & 2000 & 1.5 & 25 \\
M 2-1 & 0.8 & 0.169 & 0.5 & 2000 & 1.5 & 25 \\
M 2-2 & 1.2 & 0.190 & 0.5 & 2000 & 1.5 & 25 \\
M 2-3 & 1.5 & 0.200 & 0.5 & 2000 & 1.5 & 25 \\
M 3-1 & 0.8 & 0.268 & 0.5 & 2000 & 1.5 & 25 \\
M 3-2 & 1.2 & 0.292 & 0.5 & 2000 & 1.5 & 25 \\
M 3-3 & 1.5 & 0.308 & 0.5 & 2000 & 1.5 & 25 \\
\hline \hline
\end{tabular}

Table 7 Surface roughness of simulated surfaces

\begin{tabular}{|c|c|c|c|c|c|c|c|c|c|c|c|c|c|c|c|c|c|c|}
\hline simulated & $\mathrm{T}$ & $\mathrm{M}$ & $\mathrm{T}$ & $\mathrm{M}$ & $\mathrm{T}$ & $\mathrm{M}$ & $\mathrm{T}$ & $\mathrm{M}$ & $\mathrm{T}$ & $\mathrm{M}$ & $\mathrm{T}$ & $\mathrm{M}$ & $\mathrm{T}$ & $\mathrm{M}$ & $\mathrm{T}$ & $\mathrm{M}$ & $\mathrm{T}$ & $\mathrm{M}$ \\
surfaces & $1-1$ & $1-1$ & $1-2$ & $1-2$ & $1-3$ & $1-3$ & $2-1$ & $2-1$ & $2-2$ & $2-1$ & $2-3$ & $2-3$ & $3-1$ & $3-1$ & $3-2$ & $3-2$ & $3-3$ & $3-3$ \\
\hline $\mathrm{R}_{\mathrm{q}} / \mu \mathrm{m}$ & 0.3 & \multicolumn{2}{|c|}{0.3} & \multicolumn{2}{|c|}{0.3} & \multicolumn{2}{|c|}{0.8} & \multicolumn{2}{|c|}{0.8} & \multicolumn{2}{|c|}{0.8} & 1.4 & 1.4 & 1.4 \\
\hline
\end{tabular}

\subsection{Average surface gap}

The variations of the average surface gap of turned and milled surfaces with respect to the average pressure are delineated in Fig. 13 and Fig. 14, respectively. Fig. 13 and Fig. 14 show the relationship between $\Gamma$ and L of simulated surfaces. For turned surfaces and milled surfaces, it is evident that the average gap decreases with increasing the average pressure. In addition, the curves appear to be steeper with increasing roughness (from T 1-1, T 1-2, T 1-3/ M 1-1, M 1-2, M 1-3 surfaces to T 3-1, T 3-2, T 3-3/ M 3-1, M 3-2, M 3-3 surfaces) and become smooth with increasing pressure (L equals 0.1 to 1 ). This phenomenon can be explained as: at a low pressure, asperity peaks are sufficient to support the applied load which causes the deformation in the elastic zone [27]. On the other hand, as more and more asperities plastically deformed under high pressure, the surface stiffness becomes higher [33]. According to the results derived from Fig. 13 and Fig. 14, it can be clarified that at a constant $R_{\mathrm{q}}$, the different interval of the machined texture has little influence on the value of average gap. The explanation of these phenomena can be given as follow: In this contact model, the contact almost occurred on the peak of the surface texture which has a small proportion of surface, leading the peak of the texture to have fully deformation; as the contact area was suffered great local stress, the deformation of surface textures with same $R_{\mathrm{q}}$ would tend to be similar. 


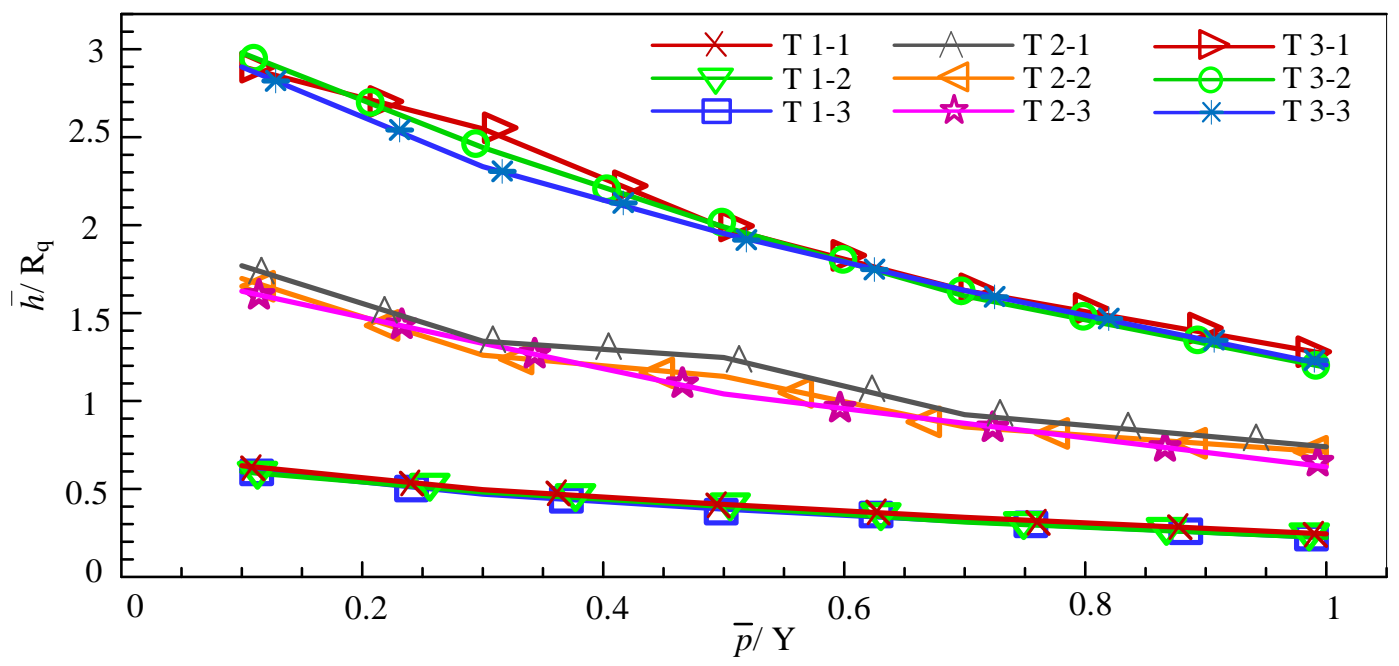

Fig. 13. The relationship between $\Gamma$ and $L$ of turned surfaces

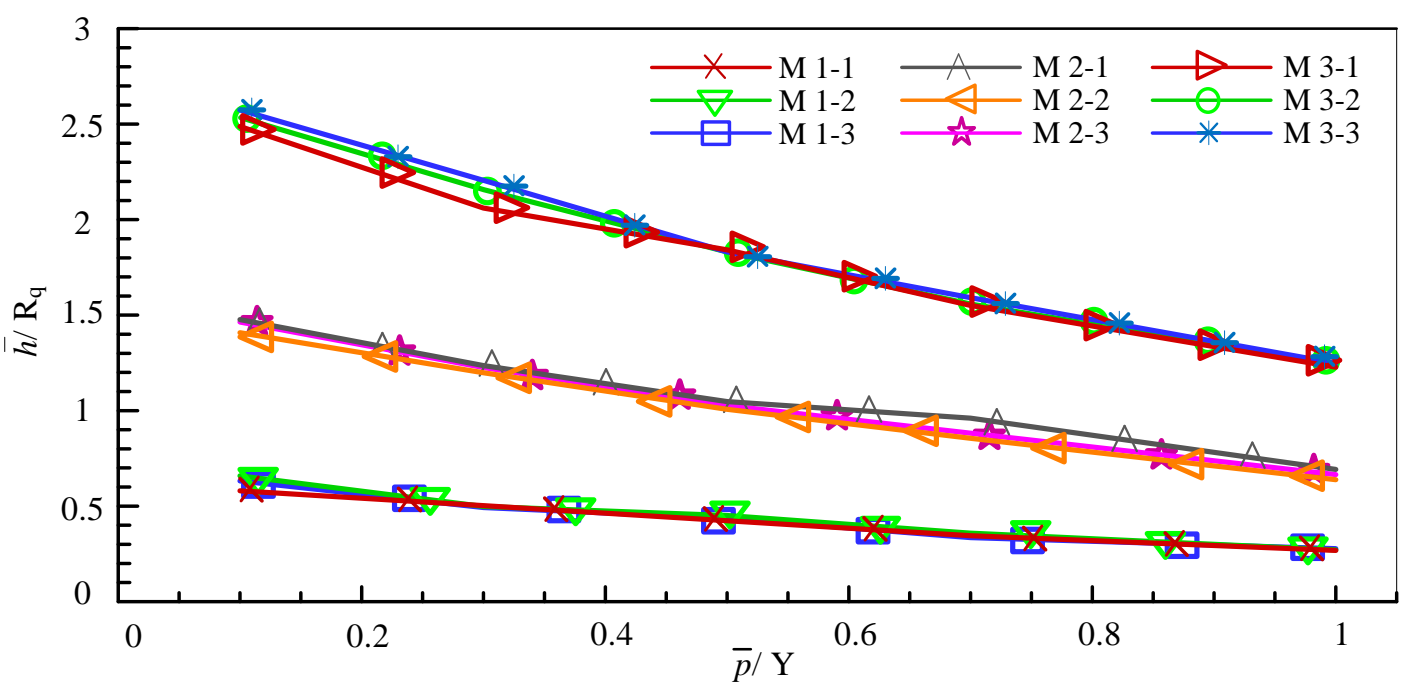

Fig. 14. The relationship between $\Gamma$ and $L$ of milled surfaces

\subsection{Contact area ratio}

It is believed that real contact areas are the places where gap vanishes and contact pressure occurs. The information of the ratio of contact area over nominal area is helpful for the investigation of friction, adhesion and wear. Fig. 15 represents the variations of the contact area ratio $(\Lambda)$ as a function of the average pressure (L). For turned surfaces, the average contact ratio decreased with increasing the surface texture interval under constant roughness (Fig. 15a-c). In addition, difference between three curves tends to be greater as the average pressure increases. In the case of milled surfaces, it has been found that the surface texture interval affected the average contact ratio. For instance, the surface with greater interval of processing texture always shows lower contact area ratio at constant roughness. It is obvious that milled surfaces displayed more irregularities compared to the turned surfaces (Fig. 15). One of the reasons causing this distinction may be the different shapes of cutting tool which results in the different strength of the structure. Different cutting trajectories of two processing modes may be the other aspects. From Fig. 5 and Fig. 9, it can be concluded that the turned topography has more symmetry than milled topography. 


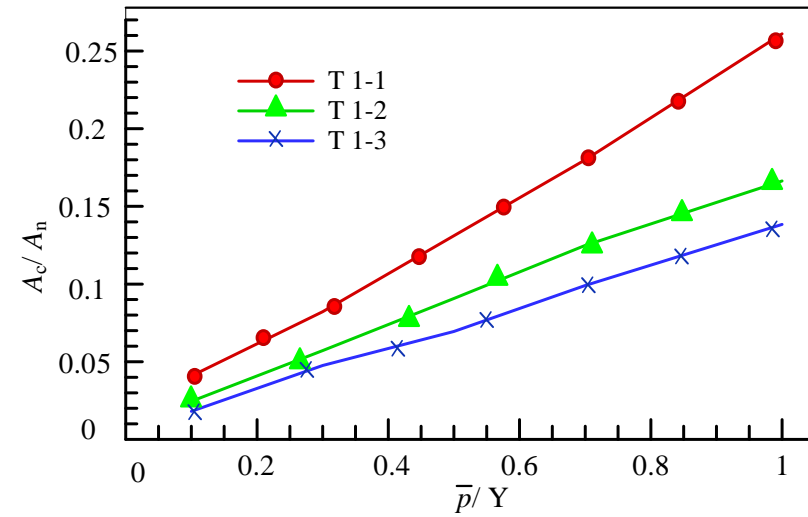

(a)

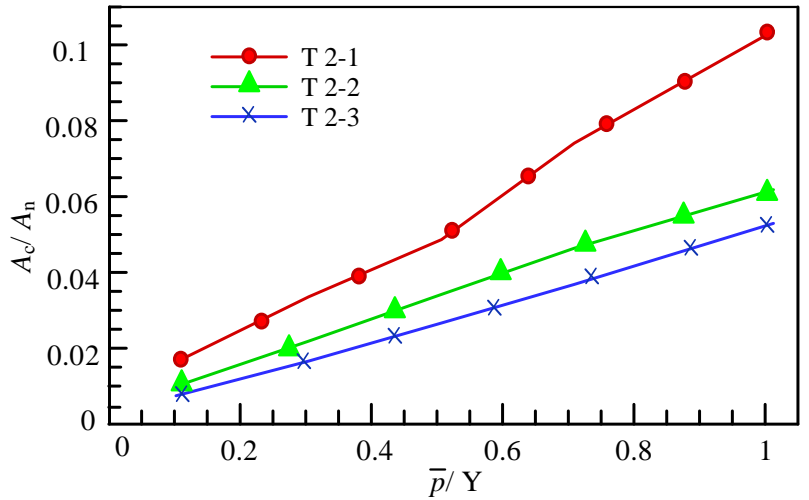

(b)

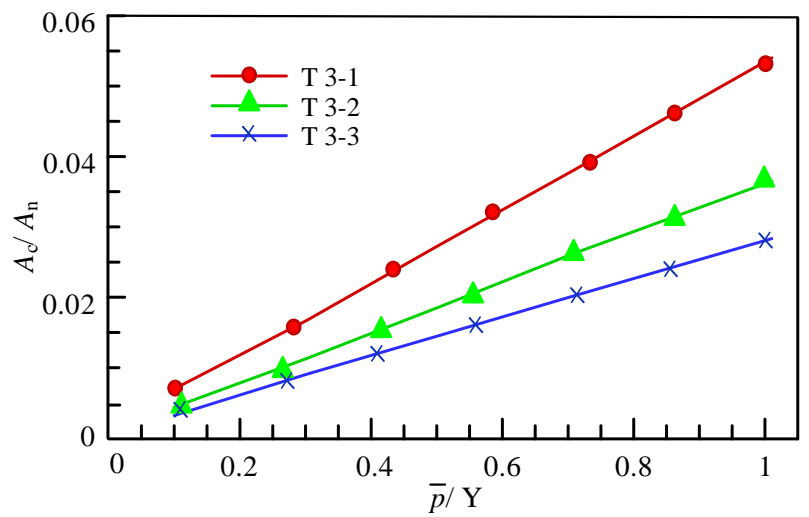

(c)

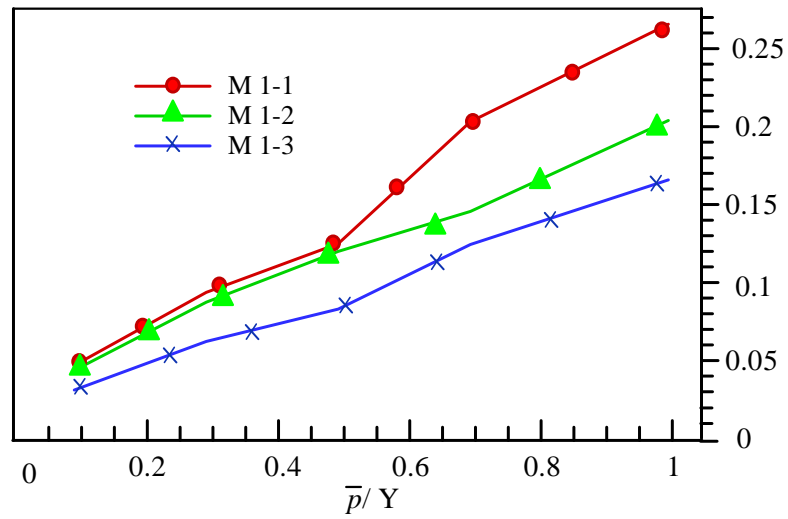

(d)

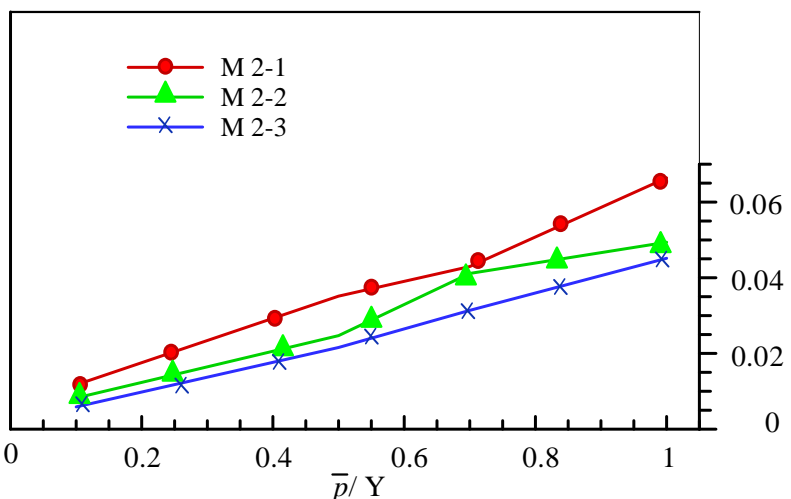

(e)

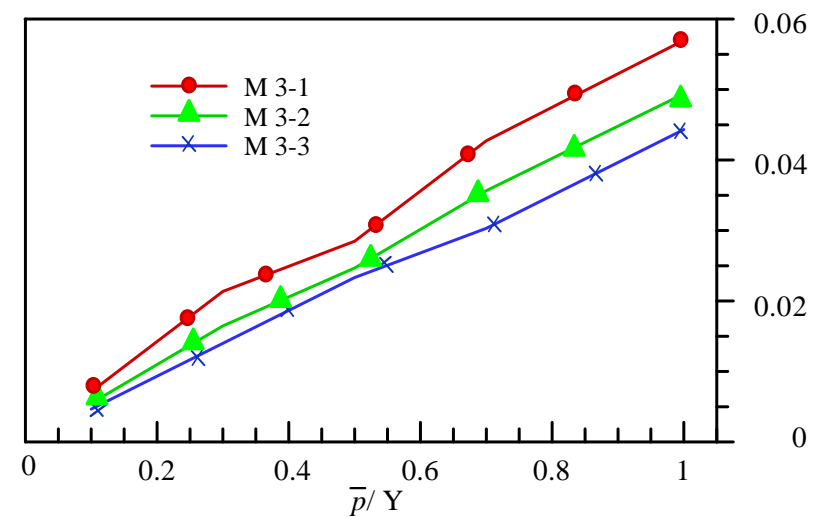

(f)

Fig. 15. The relationship between $\Lambda$ and $L$ of turning surfaces (a-c) and of milling surfaces (d-f)

\subsection{Plastically deformed volume}

The plastically deformed volume, $\mathrm{V}_{\mathrm{p}}$, is an index used to measure the plastic deformation volume. This index may offer an insight into the investigation of wear and fatigue phenomena. In the study, the plastically deformed volume was normalized by the product of nominal area, $A_{n}$ and surface roughness, $R_{q}$. Fig. 16 shows the plastically deformed volume with respect to the input variables. It can be found that all surfaces (turning and milling) show the same trend, i.e. with increasing the average pressure and surface texture interval, the dimensionless plastic volume decreased. Further, the value of $\Omega$ becomes lower with increasing the surface roughness. 


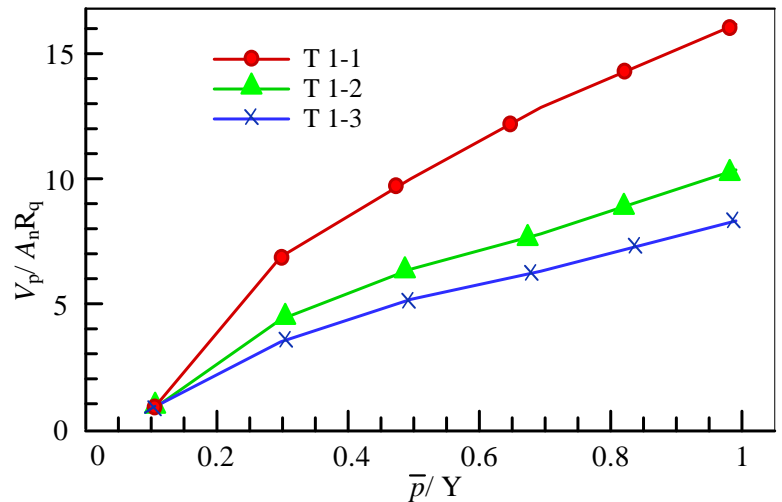

(a)

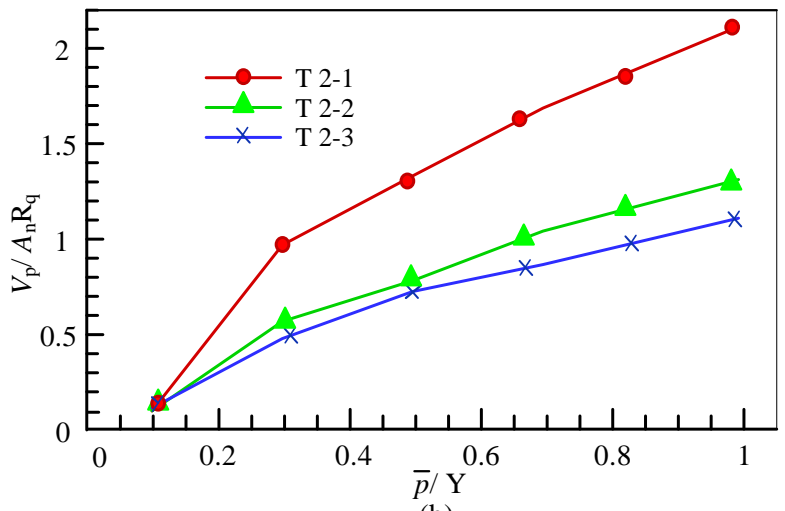

(b)

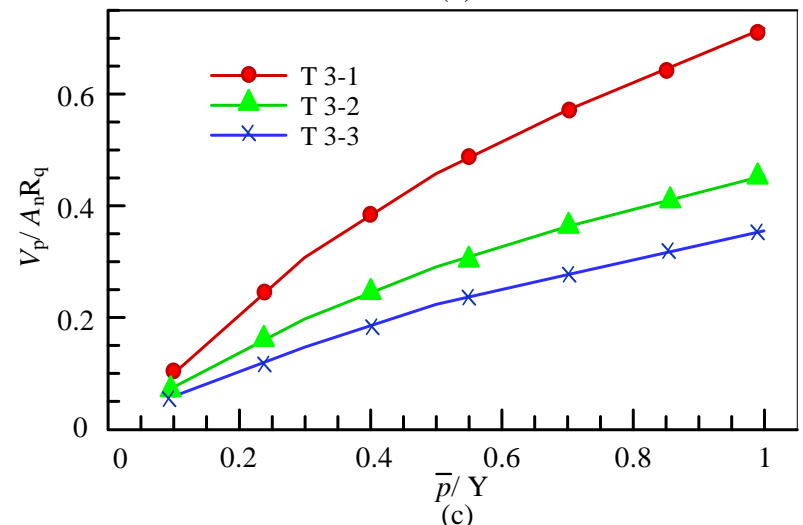

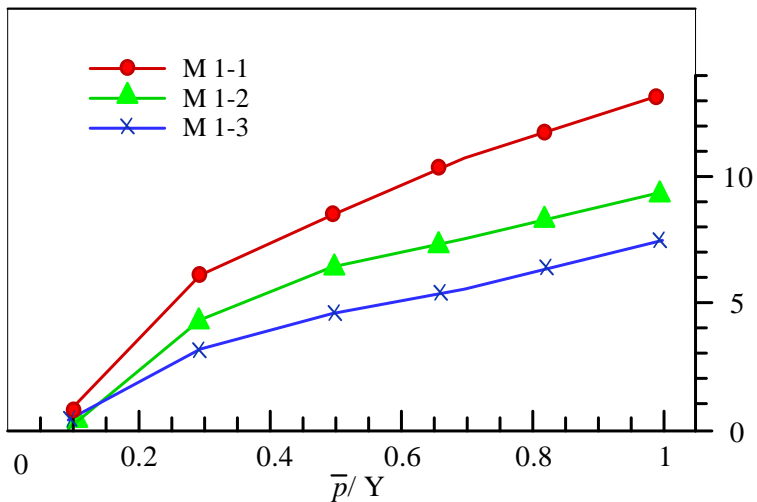

(d)

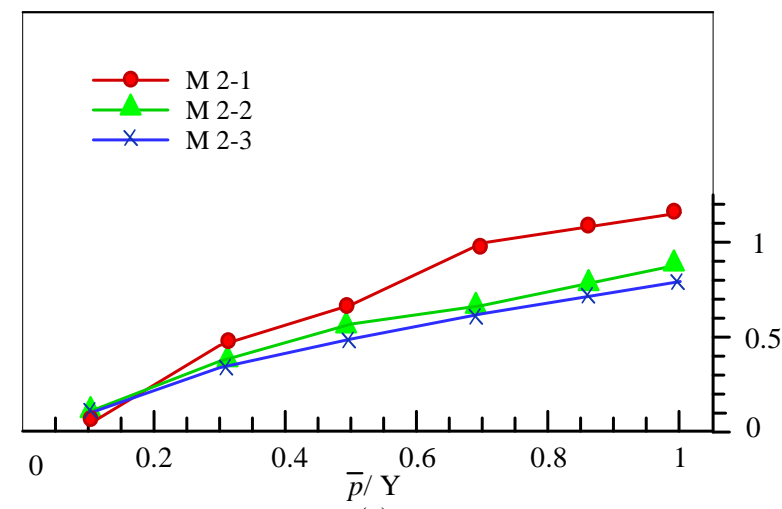

(e)

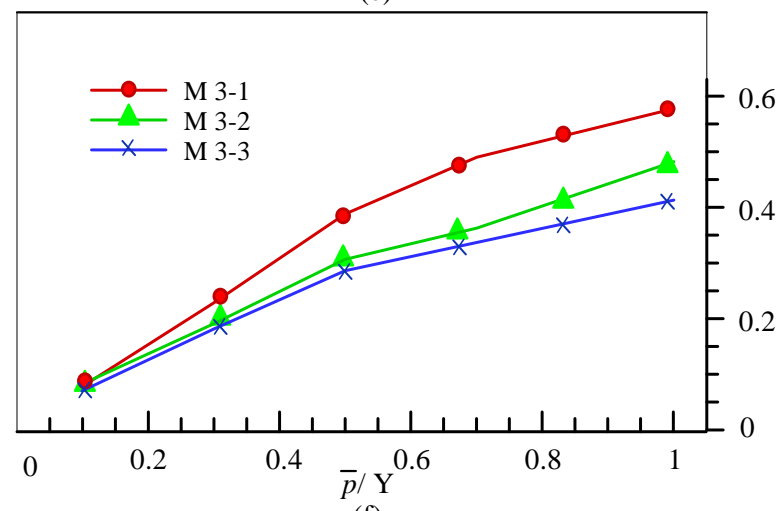

(f)

Fig. 16. The relationship between $\Omega$ and $L$ of surfaces

\subsection{Maximum von-Mises stress}

Fig. 17 represents the relationship between maximum von-Mises stress and average pressure. The variations of the curves obtained from turned surfaces are getting smaller as the surfaces tend to be rough (Figs. 17(a-c)). On the contrary, the variations of the curves obtained from milled surfaces would be more with increasing the surface roughness (Figs. 17(d-c)). Thus, it can be concluded that the different interval of the surface texture may cause the different mechanical performance despite of the same roughness. 


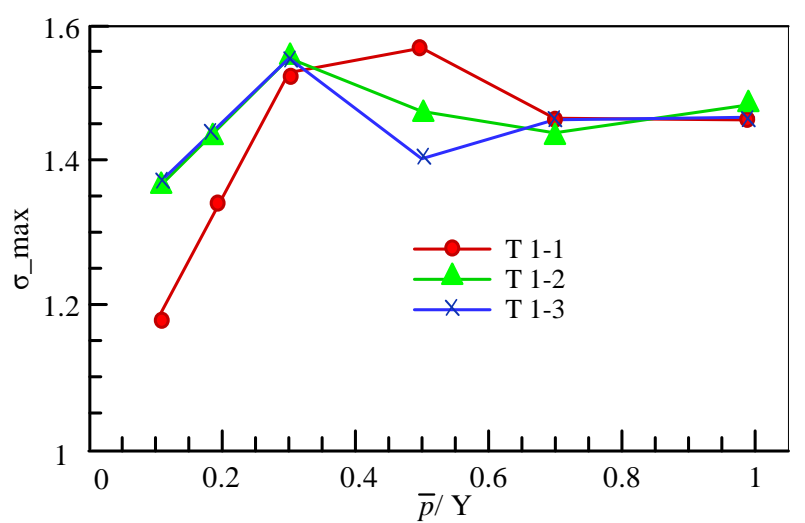

(a)

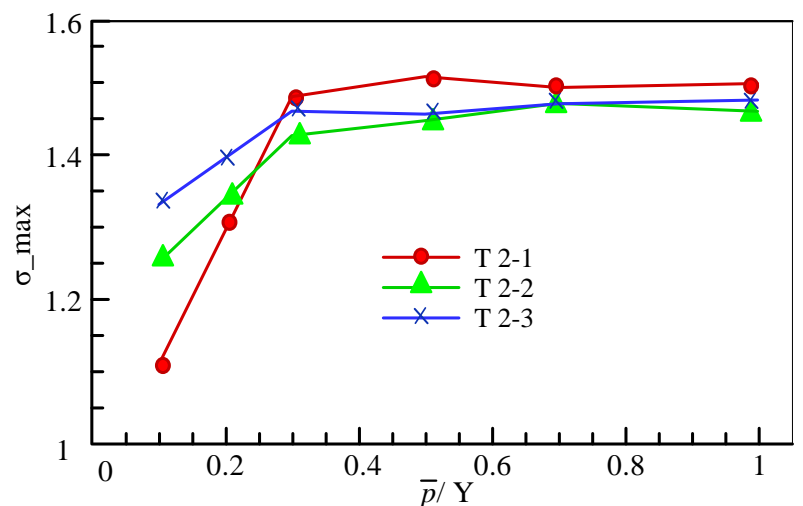

(b)

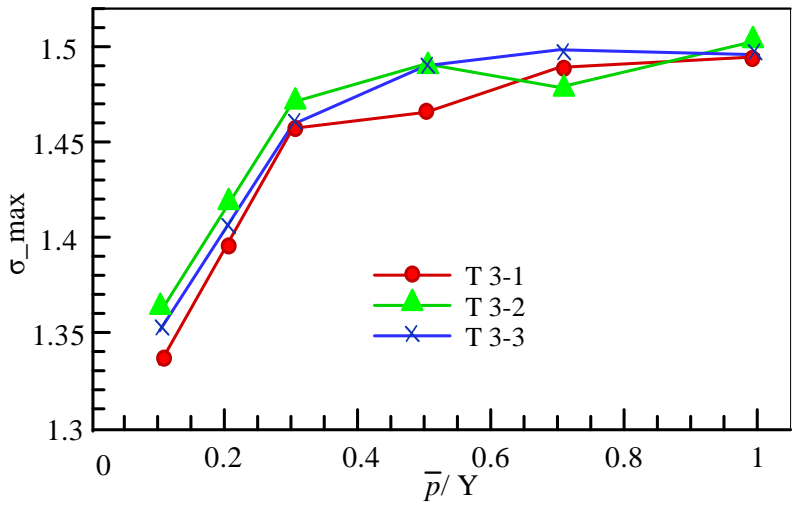

(c)

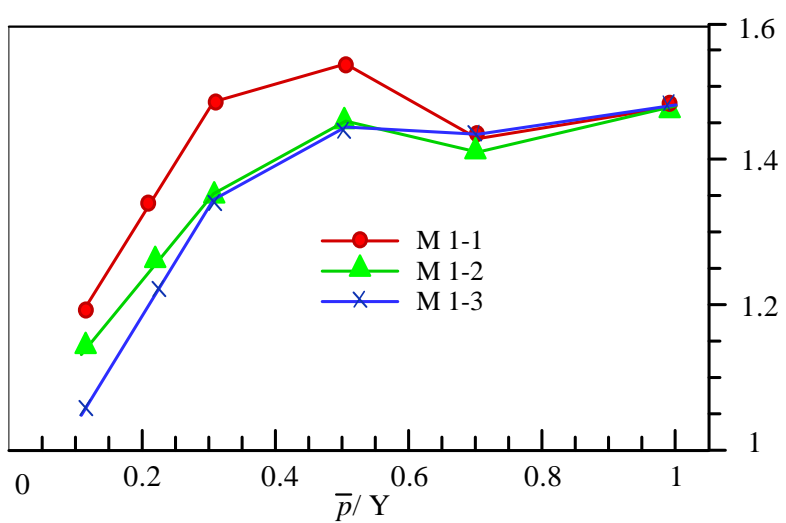

(d)

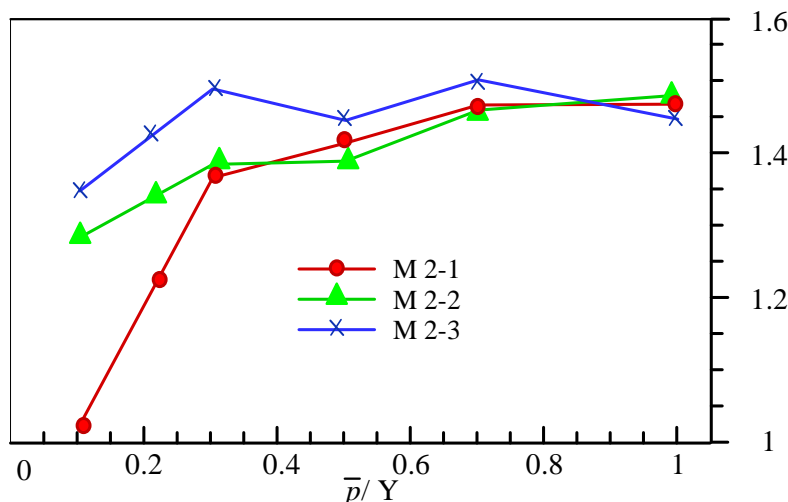

(e)

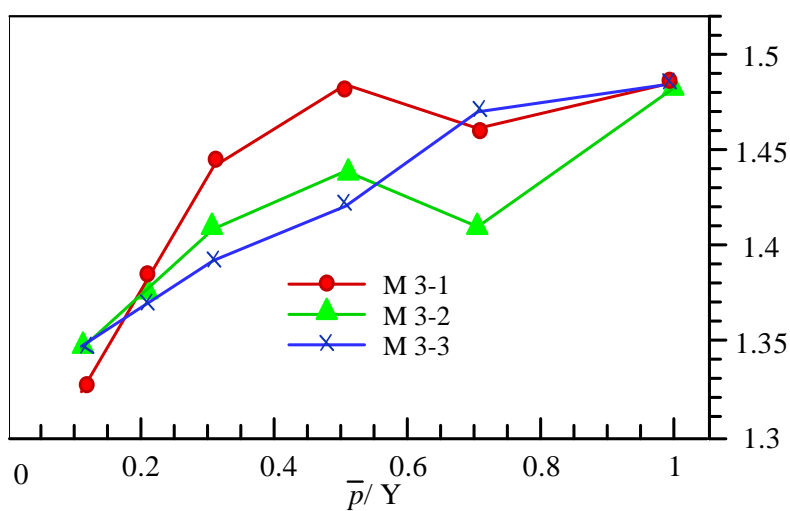

(f)

Fig. 17. The relationship between $\sigma \_\max$ and $L$ of surfaces

\section{Conclusions}

In this study, a three-dimensional numerical model, based on the SAM and minimization of complementary energy, was used to simulate the elasto-plastic contact of two nominally flat surfaces. A set of contact simulations were conducted to examine the influences of machined surface topography on contact performance. A wide range of turning and milling surfaces with different morphologies were generated by means of the simulation on machined surfaces. The simulated surface can be generated depending on the trajectory of the cutter. The cutting effect factors were took into account, such as spindle runout, cutting tool vibrations in both radial and speed directions. By analyzing the contact results of simulated surfaces, the following conclusions can be drawn:

- Loaded pressure plays the most important role in influencing the contact behavior of nominally flat surfaces.

The average gap tends to decrease as the average pressure increases. The more roughness, the steeper the curves would be and the curves are smoother as the average pressure increasing. 
- For turned surfaces, under the same condition of roughness, the average contact ratio decreases with increasing the interval of surface texture; the difference tends to be higher as the average pressure increases. In case of milled surfaces, the interval of surface texture also affects the average contact ratio. The surface with higher interval of processing texture always has a lower value of contact area ratio.

- It can be found out that both turned surfaces and milled surfaces show the same trend of dimensionless plastic volume. For example, with increasing the average pressure and the interval of the surface texture, the dimensionless plastic volume decreases at constant roughness.

- The results also demonstrate that the variation of cutting conditions also changes the contact behaviors. All the results indicate that different machined textures generated by different cutting conditions have a significant influence on the contact performances of machined surfaces.

\section{Acknowledgements}

The authors would like to thank support from the Shaanxi Provincial Department Education Key Laboratory Foundation of China (15JS067), State Key Laboratory of Mechanical Transmission Open Foundation (SKLMT-KFKT-201415), and National Science Foundation of China (51275407, 51375381, 51565053).

\section{References}

[1] Wang QJ, Zhu D, Zhou R, Hashimoto F. Investigating the Effect of Surface Finish on Mixed EHL in Rolling and Rolling-Sliding Contacts. Tribology Transactions. 2008;51:748-61.

[2] Wang T, Wang L, Zheng D, Zhao X, Gu L. Numerical Simulation Method of Rough Surfaces Based on Random Switching System. Journal of Tribology. 2015;137:021403.

[3] Makadia AJ, Nanavati JI. Optimisation of machining parameters for turning operations based on response surface methodology. Measurement. 2013;46:1521-9.

[4] Kumar NS, Shetty A, Shetty A, K A, Shetty H. Effect of Spindle Speed and Feed Rate on Surface Roughness of Carbon Steels in CNC Turning. International Conference on Modeling, Optimization and Computing (ICMOC 2012): Procedia Engineering; 2012. p. 691-7.

[5] Matsumoto Y, Hashimoto F, Lahoti G. Surface Integrity Generated by Precision Hard Turning. CIRP Annals Manufacturing Technology. 1999;48:59-62.

[6] Agha SR, Liu CR. Experimental study on the performance of superfinish hard turned surfaces in rolling contact. Wear. 2000;244:52-9.

[7] Javidi A, Rieger U, Eichlseder W. The effect of machining on the surface integrity and fatigue life. International Journal of Fatigue. 2008;30:2050-5.

[8] Lin SC, Chang MF. A study on the effects of vibrations on the surface finish using a surface topography simulation model for turning. Machine Tools and Manufacture 1998: 763-82.

[9] Kelly K, Young P, Byrne G. Modelling the influence of machining dynamics on surface topography in turning. Mechanical Sciences 1999:507-26.

[10] Yao Y, Zhao H, Li J, Yuan Z. Modeling of virtual workpiece with machining errors representation in turning. Journal of Materials Processing Technology. 2006;172:437-44.

[11] Cheung CF, Lee WB. Modelling and simulation of surface topography in ultra-precision diamond turning. 
Engineering Manufacture. 2000;214:463-80.

[12] Clocke F, Raedt H-W, Hoppe S. 2D-FEM Simulation of the Orthogonal High Speed Cutting Process. Machining Science and Technology. 2001;5:323-40.

[13] Zhou L, Cheng K. Dynamic cutting process modelling and its impact on the generation of surface topography and texture in nano/micro cutting. Engineering Manufacture. 2009;223:247-66.

[14] Kim BH, Chu CN. Texture prediction of milled surfaces using texture superposition method. Computer-Aided Design. 1999:485-94

[15] Campomanes ML, Altintas Y. An Improved Time Domain Simulation for Dynamic Milling at Small Radial Immersions. Manufacturing Science and Engineering. 2003;125:416-22.

[16] Xu A-P, Qu Y-X, Zhang D-W, Huang T. Simulation and experimental investigation of the end milling process considering the cutter flexibility. International Journal of Machine Tools and Manufacture. 2003;43:283-92.

[17] Imani BM, Layegh E. Comprehensive Simulation of Surface Texture for an End-Milling Process. Scientia Iranica. 2008.

[18] Lavernhe S, Quinsat Y, Tournier C, Lartigue C, Mayer R. NC-simulation for the prediction of surface finish in 5-axis High-Speed Machining. 3rd CIRP International Conference on High Performance Cutting. Dublin, Ireland: Archives-ouvertes; 2008.

[19] Quinsat Y, Sabourin L, Lartigue C. Surface topography in ball end milling process: Description of a 3D surface roughness parameter. Journal of Materials Processing Technology. 2008;195:135-43.

[20] Muñoz-Escalona P, Maropoulos PG. A geometrical model for surface roughness prediction when face milling Al 7075-T7351 with square insert tools. Journal of Manufacturing Systems. 2014.

[21] Wang QJ, Zhu D. Virtual Texturing: Modeling the Performance of Lubricated Contacts of Engineered Surfaces. Journal of Tribology. 2005;127:722.

[22] Wang QJ, Yasuda Y, Ren N, Nanbu T, Zhu D. Model-based virtual surface texturing for concentrated conformal-contact lubrication. Proceedings of the Institution of Mechanical Engineers, Part J: Journal of Engineering Tribology. 2010;224:685-96.

[23] Ren N, Zhu D, Chen WW, Liu Y, Wang QJ. A Three-Dimensional Deterministic Model for Rough Surface Line-Contact EHL Problems. Journal of Tribology. 2009;131:011501.

[24] Insperger T, Barton DAW, Stépán G. Criticality of Hopf bifurcation in state-dependent delay model of turning processes. International Journal of Non-Linear Mechanics. 2008;43:140-9.

[25] Yang G-z, Xu F, Gong Y-d, Wang W-s. Experiment and Modeling of Dynamic Response System on Virtual Lathe. Journal of Northeastern University(Natural Science). 2004;25.

[26] Hartung F, Insperger T, Stépán G, Turi J. Approximate stability charts for milling processes using semi-discretization. Applied Mathematics and Computation. 2006;174:51-73.

[27] Chen WW, Wang QJ, Liu Y, Chen W, Cao J, Xia C, et al. Analysis and Convenient Formulas for Elasto-Plastic Contacts of Nominally Flat Surfaces: Average Gap, Contact Area Ratio, and Plastically Deformed Volume. Tribology Letters. 2007;28:27-38.

[28] Liu S, Wang Q. Studying Contact Stress Fields Caused by Surface Tractions With a Discrete Convolution and Fast Fourier Transform Algorithm. Journal of Tribology. 2002;124:36.

[29] Zhang S, Wang W, Zhao Z. The effect of surface roughness characteristics on the elastic-plastic contact performance. Tribology International. 2014;79: 59-73.

[30] Liu S, Jin X, Wang Z, Keer LM, Wang Q. Analytical solution for elastic fields caused by eigenstrains in a half-space and numerical implementation based on FFT. International Journal of Plasticity. 2012;35:135-54.

[31] Jacq C, Nélias D, Lormand G, Girodin D. Development of a Three-Dimensional Semi-Analytical Elastic-Plastic Contact Code. Journal of Tribology. 2002;124:653.

[32] Li P, Wang Z, Li X, Jin X, Chen WW, Li Y, et al. Elasto-plastic indentation of a half-space by a rigid sphere under normal and torque loading. Tribology International. 2013;62:141-8. 
[33] Starzynski G, Buczkowski R. Ultrasonic Measurements of Contact Stiffness Between Rough Surfaces. Journal of Tribology. 2014;136:034503.

\section{Nomenclature}

\section{Roman Letters}

$\begin{array}{ll}A_{c}, A_{n} & \text { Real contact area, nominal contact area } \\ E & \text { Young's modulus, GPa } \\ E^{*} & \text { Equivalent Young's modulus, GPa, } E^{*}=E /\left(1-v^{2}\right) \\ E_{t} & \text { Elasto-plastic tangential modulus } \\ g(\lambda) & \text { Yield strength, MPa } \\ G & \text { Green's functions } \\ h, h_{i} & \text { Surface gap, initial gap, mm } \\ L=\bar{p} / Y & \text { Dimensionless average pressure } \\ p & \text { Surface pressure } \\ R_{q} & \text { Root mean square of roughness (RMS), } \mu m \\ u_{3}, u_{3}^{p} & \text { Total normal displacement, elastic normal displacement } \\ S_{i j} & \text { deviatoric stress } \\ Y & \text { Initial yield strength without strain hardening } \\ R & \text { Tool radius }\end{array}$

\section{Greek Letters}

$\Gamma=\bar{h} / R_{q} \quad$ Dimensionless average surface gap

$\varepsilon_{i j}^{p} \quad$ Plastic strain component

$\lambda \quad$ Accumulative effective plastic strain

$\Lambda=A_{c} / A_{n} \quad$ Contact area ratio

$v \quad$ Poisson ratio

$\sigma_{i j}, \sigma_{i j}^{e}, \sigma_{i j}^{p} \quad$ Cauchy stress, elastic and residual stress, MPa

$\sigma_{V M} \quad$ von-Mises equivalent stress, MPa

$\delta \quad$ Contact interference, $\mathrm{mm}$

$\Omega=V_{p} / A_{n} R_{q}$ Dimensionless plasticity volume 